\title{
MANUTENÇ̃̃o PREDIAL: ANÁLISE DA QUALIDADE NAS EDIFICAÇÕES E A SUA INFLUÊNCIA NOS USUÁRIOS EM PORTO ALEGRE (RS)
}

\author{
PRIETTO, ÉMERSON \\ Especialista em Produção Civil \\ PUCRS \\ Rio Grande do Sul; Brasil \\ emerson.prietto@gmail.com
}

\author{
ANDRADE, JAIRO \\ Professor \\ PUCRS \\ Rio Grande do Sul; Brasil \\ jairo.andrade@pucrs.br
}

\section{RESUMO}

A manutenção predial bem planejada e executada proporciona manutenção da vida útil e do desempenho das edificações, porém a impressão é a de que falta este conhecimento aos construtores e gerenciadores, o que origina intervenções emergenciais. Além disso, pode também influenciar na sensação de bem-estar das pessoas propiciando ambientes bem conservados. É necessário que a manutenção predial preventiva cresça no mercado pois somente com ela é possível manter os níveis de desempenho exigidos pela atual norma de desempenho. Por este cenário e pelas motivações expostas, esta pesquisa tem como objetivo entender como as empresas e condomínios tratam da manutenção em suas edificações e tentar qualificá-la a partir da opinião dos usuários, através da aplicação de questionários. Os resultados apresentaram que a maioria das empresas não possui programa de manutenção, com exceção das empresas de manutenção. Segundo as informações apresentadas pelos usuários, a melhor gestão de manutenção é a realizada pelos shoppings e a pior é a realizada pelas indústrias. Quase a totalidade afirmou que o estado de conservação interfere no seu conforto, que evitam retornar a locais com más condições e a maioria afirmou que não se importa em pagar um pouco a mais por serviços de melhor qualidade.

Palavras-chave: Manutenção predial, desempenho, percepção do usuário

\begin{abstract}
Well planned and executed building maintenance provides maintenance of the useful life and performance of buildings, but the impression is that builders and managers lack this knowledge, which leads to emergency interventions. Moreover, it can also influence people's sense of well-being by providing well-maintained environments. It is necessary that preventive building maintenance grows in the market because only with it is possible to maintain the levels of performance required by the current performance standard. Because of this scenario and the motivations exposed, this survey aims to understand how companies and condominiums deal with maintenance in their buildings and try to qualify it from the users' opinion, through the application of questionnaires. The results showed that most companies do not have a maintenance program, except for the maintenance companies. According to the information presented by the users, the best maintenance management is the one performed by the shopping malls and the worst is the one performed by the industries. Almost all stated that the state of conservation interferes with their comfort, that they avoid returning to places with bad conditions and most said they do not mind paying a little more for better quality services.

Keywords: Building maintenance, performance, user's perception.
\end{abstract}

\section{INTRODUÇÃO}

O conceito de manutenção surgiu focado para máquinas e equipamentos nos diversos processos fabris, com o intuito de manter o desempenho da produção ao longo do tempo evitando os tempos de parada. Foi neste cenário industrial que apareceram as teorias e os métodos sobre manutenção, e que recentemente começaram a ser aplicados nas edificações (VILLANUEVA, 2015).

Hoje existem empresas que prestam o serviço de gerenciamento da manutenção predial para condomínios residenciais e comerciais, auxiliando no gerenciamento do programa de manutenção. Porém, ainda não possuem grande atuação, pois 
segundo Silva (2014), a manutenção de edificações ainda está contra a cultura atual de que o processo construtivo se encerra no momento da entrega e operação do edifício, enquanto que as atividades de manutenção são necessárias para manter o desempenho da construção de maneira econômica.

Apesar das dificuldades em aplicar um programa de manutenção predial, é de grande importância que isto seja feito devido aos benefícios que ele oferece, tanto para os usuários quanto para os construtores. Villanueva (2015) cita que os usuários ganham com um imóvel melhor avaliado, com maior vida útil e mais segurança dos sistemas e dos equipamentos, além da economia, enquanto que os construtores ganham com o prestígio por oferecer um produto de boa qualidade, e mostrar a preocupação com a manutenção do desempenho das suas edificações.

Os benefícios de um programa de manutenção bem estruturado e bem executado podem não ser tão claros, pois como afirma Castro (2007) os investimentos não são visíveis. Logo, os ganhos são percebidos apenas quando há um planejamento que aponte os resultados que podem ser alcançados. Fora isto, Scopel (2015) indica que o estado de conservação e a arquitetura dos ambientes influenciam nas sensações dos usuários, sendo então mais um motivo para manutenção predial de boa qualidade.

Portanto, com estas afirmações a respeito da importância da manutenção predial, aliado com o desinteresse por parte de quem constrói e com a falta de informação por parte dos usuários, esta pesquisa tem como tema o panorama da manutenção predial nas edificações. Neste contexto, o objetivo principal é identificar como é realizada a manutenção predial por parte dos administradores nos condomínios e por parte das empresas comerciais e industriais em suas sedes e qualificá-la através da opinião dos usuários. Esta pesquisa deseja também descobrir a importância que os usuários dão para as condições de manutenção nas edificações que frequentam, através de questionário.

Para a realização de um trabalho dessa natureza algumas delimitações são necessárias. Neste trabalho não serão indicadas práticas de gestão de manutenção predial e não irá realizar comparações de custos entre situações diferentes de manutenção, detalhar procedimentos de manutenção e tão pouco elaborar um programa de manutenção.

\section{PROCEDIMENTOS METODOLÓGICOS}

\subsection{Método de pesquisa}

Esta seção do trabalho busca classificar o método de pesquisa sob os pontos de vista da natureza, da abordagem do problema, dos objetivos e dos procedimentos técnicos. Além disso, também são apresentadas nesta seção as etapas do trabalho.

Classificando-se a pesquisa sob o ponto de vista de sua natureza diz-se que é uma pesquisa aplicada, pois tem a intenção de gerar informações e conhecimentos através dos questionários aplicados junto às empresas e aos usuários, para que se possa entender as necessidades da manutenção predial sob estes dois lados. A abordagem do problema da pesquisa será quantitativa pois as conclusões serão realizadas a partir da análise das respostas dos questionários de forma que os dados possam ser classificados e comparados como números. Quanto ao seu objetivo, a pesquisa será descritiva, pois utilizará os questionários para obter as respostas que depois serão analisadas para tentar descrever como as empresas realizam a gestão da manutenção predial e a opinião dos usuários em relação a isto, ou seja, descrever a forma que é praticada no mercado.

\subsection{Método de trabalho}

Para se alcançar o objetivo principal da pesquisa será empregado o levantamento, com os questionários a fim de conhecer o comportamento das empresas e dos usuários. As etapas da pesquisa encontram-se apresentadas na Figura 1. 


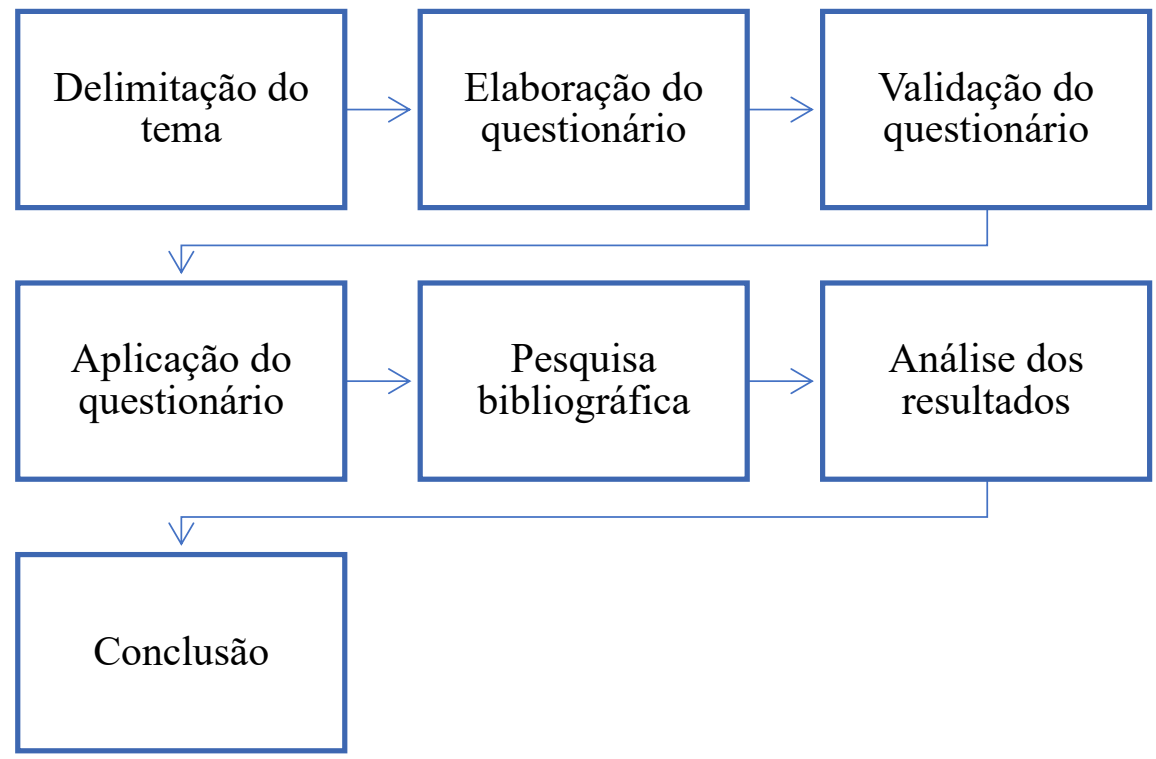

Figura 1: Etapas do trabalho

A delimitação do tema se deu através da observação do mercado das indústrias do estado em visitas de cunho profissional. Verificou-se então o mau estado de conservação das edificações, levando ao questionamento pessoal sobre quais os motivos que levam isto, motivando esta pesquisa para entender como é feita a gestão da manutenção predial e porque os maus resultados encontrados. Ao longo do desenvolvimento da pesquisa, o tema foi se abrangendo também a outras edificações e a qualidade atribuída pelos usuários.

A elaboração do questionário foi dividida em dois momentos. Inicialmente foi moldado o instrumento de coleta de informações junto as empresas, com dois tipos de questões: de múltipla escolha sobre a gestão da manutenção predial aplicada, e com questões abertas, a fim de se obter informações relevantes sobre a questão da terceirização da manutenção.

$\mathrm{Na}$ sequência o questionário aos usuários foi estruturado com questões de múltipla escolha, com a técnica de Preferência Revelada, na qual, segundo Spindler (2011, apud TRIERVEILER, 2015), o entrevistado dá as suas opiniões a respeito de situações reais vividas, que no caso deste estudo seria sobre o estado de conservação das edificações que frequenta e se isto é um fator determinante para frequentá-las novamente. Utilizou-se também da técnica de Preferência Declarada, que segundo Senna e Michel (2010, apud TRIERVELIER, 2015) tem como objetivo coletar do entrevistado sua expectativa em relação a alguma situação proposta, para constatar se os usuários se importam em pagar a mais por serviços de melhor qualidade. Além disso, também foram elaboradas questões semelhantes a escala de Lickert para coletar dos usuários a sua satisfação em relação a determinados ambientes. Esta escala, segundo SurveyMonkey (2016), se utiliza de opções de resposta que variam de um extremo ao outro conforme alguma legenda apresentada. Os questionários foram elaborados com a ferramenta Formulários Google, devido à sua simplicidade de elaboração e gratuidade de uso.

Após isto, os questionários foram aplicados a um grupo de 5 entrevistados para identificar dificuldades de interpretação que poderiam ocorrer durante o preenchimento, visando validar o questionário. Após as correções necessárias, os questionários foram enviados por e-mail para diferentes profissionais e empresas, sendo que no caso das empresas, foi realizado contato telefônico para aumentar a porcentagem de respostas. Os questionários foram elaborados na segunda quinzena do mês de agosto e aplicados entre o início de setembro e o final de novembro de 2016.

\section{RESULTADOS E DISCUSSÃO}

\subsection{Questionário para as empresas: Diagnóstico da manutenção predial no Estado do Rio Grande do Sul}

Este questionário foi respondido por 13 empresas, tendo sido enviado para 42 via e-mail, após contato prévio por telefone, obtendo-se uma taxa de resposta de $30,95 \%$. A primeira seção do questionário teve como objetivo identificar as empresas, de forma que posteriormente pudessem ser agrupadas a fim de procurar tendências nas respostas entre os 
grupos. Três perguntas compunham esta seção: qual o ramo da empresa, qual faixa de número de funcionários e qual a relação com manutenção predial, se presta serviços para terceiros ou se realiza manutenção do seu pavilhão, por exemplo.

Após estas perguntas para identificação, foi perguntado como é realizado o controle da manutenção e as respostas estão apresentadas na Figura 2. Analisando cada uma das empresas e as suas respostas, percebe-se que das 12 que responderam a questão, 8 não possuem a manutenção como sua finalidade, sendo então, por exemplo, indústrias ou hospitais, e destas, apenas 2 possuem execução terceirizada. Considerando-se o que fora discutido no referencial teórico, empresas em que a manutenção não valoriza o produto final podem ter benefícios ao terceirizar este serviço para poder focar esforços e investimentos na sua atividade principal. A terceirização será melhor discutida ao final deste questionário com uma pergunta específica.

\title{
Como é realizado o controle da manutenção predial na empresa?
}

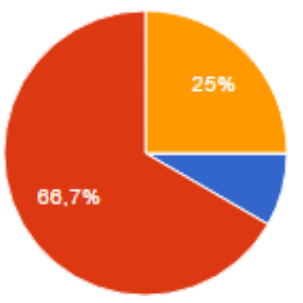

\author{
Não há um setor específico. $1 \quad 8.3 \%$ \\ Gestão e execução próprias. $8 \quad 66.7 \%$ \\ Gestão própria e execução terceirizada. $3 \quad 25 \%$ \\ Gestão e execução terceirizadas. $\quad 0 \quad 0 \%$
}

Figura 2: Pergunta do questionário aplicado as empresas

A próxima questão perguntava se a empresa possui um programa de manutenção com atividades preventivas prédeterminadas. Houveram 12 respostas, das quais 7 (58,3\%) assinalaram que não possuem programa de manutenção. Entre estas empresas estão as indústrias, mostrando que não possuem o conhecimento da necessidade do programa. Das $5(41,7 \%)$ que afirmaram ter um programa de manutenção, estão todas as empresas de reforma ou manutenção, mostrando que conhecem a necessidade e aplicam no seu exercício. Outra informação é que destas 5, 4 são empresas de médio ou grande porte, mostrando a tendência de que investimentos em manutenção podem ser caros e exigem planejamento e disponibilidade de recursos, mais comuns em empresas destes portes.

As empresas que afirmaram ter programa de manutenção assinalaram quais os sistemas ou elementos possuem intervenções preventivas. A cobertura foi a mais assinalada, por 5 empresas, seguida por instalações elétricas, fachadas, impermeabilização, instalações de climatização e elevadores, com 4 marcações. Estes três últimos são normalmente fornecidos e instalados por empresas especializadas, que dependendo da negociação podem realizar o serviço de reposição ou manutenção, o que pode explicar o fato de terem mais intervenções preventivas. Cobertura, instalações elétricas e fachadas tem importantes papéis nas edificações, seja pelo aspecto funcional dos dois primeiros, ou pelo aspecto estético da fachada. Instalações elétricas ainda sofrem alterações no seu projeto devido a mudanças de layout dos ambientes, por exemplo, o que oportuniza que as intervenções sejam realizadas no mesmo momento. O único elemento não assinalado foi a fundação, provavelmente pela dificuldade de acesso ao local para inspeções ou intervenções.

Das 7 empresas que não possuem programa, 6 afirmaram que realizam manutenção após ocorrer alguma manifestação patológica, sendo que destas, 2 disseram que realizam algum tipo de monitoramento dos sistemas. Apenas uma empresa disse que acompanha os prazos predeterminados para ações preventivas. Tais dados deixam claro que ainda é considerável a cultura de intervir apenas após as falhas com manutenção corretiva não programada, assumindo os prejuízos decorrentes.

Quando questionadas sobre a possibilidade de paralisação das atividades dos locais para realização das intervenções de manutenção, 8 (66,7\%) empresas afirmaram que não podem paralisar a edificação como um todo, mas sim os ambientes alternadamente, de forma que haja um rodízio. Isto não é um fato que impossibilite a execução dos reparos, pois um planejamento prévio é capaz de determinar a ordem das intervenções de modo que não interfira nos processos da empresa. Porém, 2 (16,7\%) afirmaram que não podem interromper as atividades e outras $2(16,7 \%)$ disseram que só é possível manutenção nos períodos de férias coletivas. Das duas indústrias que participaram da pesquisa uma afirmou não haver a possibilidade de paralisação e a outra apenas no período de férias coletivas, evidenciando uma dificuldade que já era prevista, pois paralisar algum ambiente pode ser um prejuízo na sua linha de produção causando paradas 
indesejáveis. Isto pode ser uma justificativa para o fato de elas não terem um programa de manutenção, pois não podem ter ações rotineiras, tendo que concentrar todas as intervenções em curtos períodos de tempo.

Para verificar condições de manutenabilidade das construções, foi perguntado quais os elementos que mais tem dificuldade de acesso, e as mais assinaladas foram: fachadas $(7-63,6 \%)$, instalações elétricas e cobertura $(5-45,5 \%)$ e instalações hidráulicas $(4-36,4 \%)$. Cobertura e fachadas são sistemas que precisam ter previstas na fase de projeto as formas de acesso, cujos dados mostram que os projetos ainda não preveem estas situações. O que chama a atenção é as fundações serem assinaladas por apenas 3 empresas, uma vez que é difícil ter acesso a elas.

As duas últimas perguntas eram abertas para que o respondente pudesse dar sua opinião sobre os temas propostos. A primeira perguntava se via necessidade de alteração na estrutura da manutenção predial. Seis (46,2\%) afirmaram que não viam esta necessidade, e apenas uma empresa deu alguma justificativa, dizendo que qualquer alteração geraria custos e por isso não seria necessário. Estas negativas não fornecem alguma informação mais clara pois poucos entrevistados apresentaram seus motivos, porém, pode-se entender como um desinteresse em melhorar a sua estrutura pois quase todos haviam declarado que não realizam ações preventivas, mostrando a falta de conhecimento em relação aos seus benefícios.

Os entrevistados que reconheceram a necessidade de alteração foram 7 (53,8\%), tendo as seguintes motivações: maior necessidade de manutenção preventiva, prédio antigo e quadro pessoal enxuto, novo software de gestão, criação de equipe específica e maior acompanhamento dos sistemas. O respondente que argumentou sobre o prédio ser antigo e ter poucos funcionários a disposição é responsável pela manutenção de um hospital, e se queixou de a estrutura ser aquém do necessário, uma vez que possui 8 funcionários (menos de 1\% do total do hospital) para atender uma área de $13.200 \mathrm{~m}^{2}$, necessitando de uma reorganização completa da estrutura com altos investimentos. Os outros pontos citados não são difíceis de serem implementados e são requisitos para implantação do programa de manutenção conforme a NBR 5674 (ABNT, 2012). Isto evidencia que estas empresas conhecem a realidade do mercado e sabem o que deve ser empregado conforme as boas práticas e os seus benefícios.

A última pergunta pedia a opinião sobre a estratégia de terceirização e apenas uma empresa mostrou-se contrária, afirmando que equipes próprias teriam mais respeito pelo local por fazerem parte da empresa e teriam maior sentimento de posse pelo ambiente de trabalho, o que supostamente incentivaria a busca por melhores resultados nas suas tarefas. As relacionadas com reforma ou manutenção em geral mostraram-se a favor apenas em serviços especializados ou equipamentos, pois agiliza os serviços e melhora os resultados. O restante mostrou-se a favor, principalmente empresas que não tem a manutenção como foco, pois segundo elas, dispensa estrutura com equipes próprias além da preocupação com serviços como comprar cimento e acompanhar trabalhadores, conforme citado por uma delas. Esta resposta causa contradição, pois este entrevistado havia respondido, na questão apresentada anteriormente, que possui gestão e execução próprias, mostrando que o profissional possui uma opinião contrária ao que é realizado na empresa, e isto constatou-se também em outros entrevistados, deixando claro que as pessoas envolvidas com este mercado sabem o que é preciso, mas as empresas que não tem este foco não buscam a atualização neste quesito de manutenção. Outro entrevistado afirmou ser necessária a terceirização para algumas categorias apesar de precarizar as relações de trabalho, o que se resolveria com contratos bem elaborados e efetivamente fiscalizados.

\subsection{Questionário para os usuários: Percepção dos usuários em relação a manutenção das construções}

O questionário voltado aos usuários obteve 41 respondentes, considerando um total de 105 questionários enviados, obtendo como taxa de resposta 39,05\%. Por isso, assim como no primeiro questionário, a primeira seção teve o objetivo de captar algumas informações de quem participou, como faixa etária e renda familiar.

A primeira pergunta questionava se o estado de conservação das edificações afeta o bem-estar pelo seu ponto de vista e $37(92,5 \%)$ pessoas afirmaram que sim, enquanto que $3(7,5 \%)$ foram contrários. Dos 41 participantes apenas 3 são idosos, e destes, 2 afirmaram que a conservação não os afeta e o outro idoso não respondeu esta pergunta. $O$ fato de a amostra de idosos ser pequena impossibilita que se possa concluir a partir disso, mas esta questão é algo que pode ser estudado mais especificamente, se os idosos em geral dão menos valor ao seu conforto nos ambientes.

O questionamento seguinte perguntava se o estado de conservação é um fator considerado para frequentar um local ou não. Das 39 respostas, 29 (70,7\%) disseram que sim e que inclusive pagariam a mais por isto, mas não havia a indicação de o quanto a mais seria o valor. Os outros 12 (29,3\%) entrevistados também disseram que sim, porém não pagariam a mais para isso, sendo 2 deles idosos. Analisando as respostas conforme as classes sociais, estas porcentagens mantiveram-se próximas, mostrando que as pessoas de classes sociais mais baixas não se importam em pagar um pouco a mais por serviços ou ambientes de melhor qualidade, mesmo tendo menos recursos disponíveis. A pergunta em 
nenhum momento apontou o quanto a mais seria, então deve-se considerar um baixo aumento que deveria ser incorporado na cobrança, seja na taxa de condomínio de um edifício ou no produto oferecido por uma loja ou um prato de restaurante. Estes dados servem como motivação para que as empresas em geral estudem a possibilidade de investimentos nesta área para atrair novos clientes.

A mesma pergunta foi feita em um cenário de compra ou aluguel de imóvel e as respostas estão na Figura 3. Nesta questão, diferentemente da anterior, os 3 idosos afirmaram que pagariam a mais por melhores condições e conforto nos imóveis, mostrando uma tendência de que os idosos valorizem mais o conforto nas suas moradias do que nos demais ambientes que frequentem.

\section{Ao comprar ou alugar um imóvel, a aparência dele e do seu entorno é um fator determinante?}

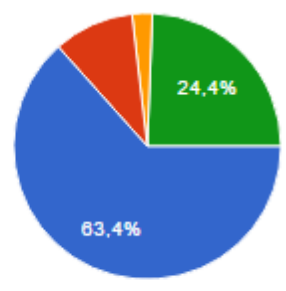

Sim, e não me importo em pagar um pouco mais. Sim, mas não pago a mais por isso. Não considero este fator.

Nunca comprei ou aluguei algum imóvel.

$\begin{array}{rr}26 & 63.4 \% \\ 4 & 9.8 \% \\ 1 & 2.4 \% \\ 10 & 24.4 \%\end{array}$

Figura 3: Pergunta do questionário aplicado aos usuários

Os usuários foram também questionados se voltariam a um local no qual estiveram pela primeira vez e que estava em más condições, e as respostas estão na Figura 4. Estes números mostram que 90,3\% das pessoas teriam alguma objeção em voltar ao estabelecimento, mostrando a importância que deve ser dada para a manutenção das condições de conforto dos ambientes em geral, para não correr o risco de perder clientes por este motivo.

\section{Ao visitar um local pela primeira vez e ver que ele não se encontra em boas condições, você voltaria a visitá-lo?}
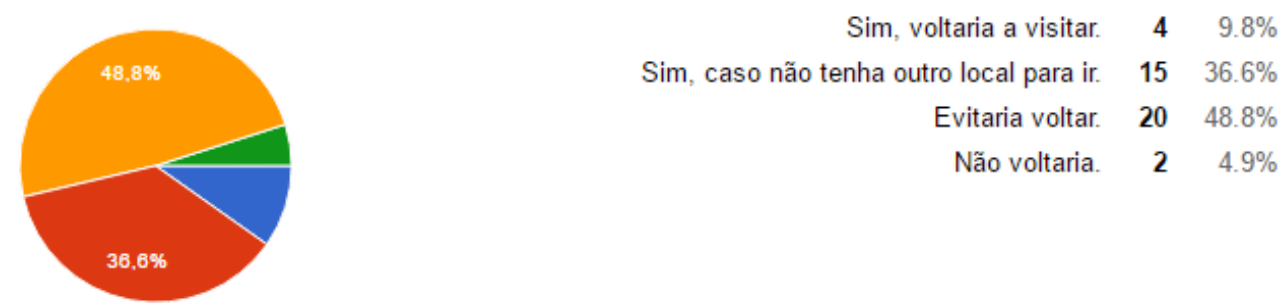

Figura 4: Pergunta do questionário aplicado aos usuários

Posteriormente, foi solicitado que os usuários atribuíssem notas a alguns tipos de edificações que eles tivessem o costume de frequentar, cujo resultado está apresentado na Figura 5. Importante salientar que os ambientes de educação e de saúde não tiveram distinção de público ou privado, que talvez pudessem apresentar resultados diferentes caso houvesse a divisão. Percebe-se que as melhores notas foram atribuídas para Restaurantes e Shopping Centers, que tem grande preocupação com satisfação dos usuários, o que explica o melhor estado de conservação e maior conforto dos usuários como forma de atrair e manter clientes. 


\begin{tabular}{|c|c|c|c|c|c|c|c|c|c|c|c|}
\hline \multirow{4}{*}{ Ambientes Construídos } & \multicolumn{11}{|c|}{ Notas atribuídas } \\
\hline & \multirow{2}{*}{\multicolumn{2}{|c|}{$\frac{1}{\text { Quantidade }}$}} & \multirow{2}{*}{\multicolumn{2}{|c|}{\begin{tabular}{c|}
2 \\
Quantidade
\end{tabular}}} & \multirow{2}{*}{\multicolumn{2}{|c|}{\begin{tabular}{|c|}
3 \\
Quantidade
\end{tabular}}} & \multirow{2}{*}{\multicolumn{2}{|c|}{$\begin{array}{c}4 \\
\text { Quantidade }\end{array}$}} & \multirow{2}{*}{\multicolumn{2}{|c|}{\begin{tabular}{|c|}
5 \\
Quantidade \\
\end{tabular}}} & \multirow{3}{*}{ Média } \\
\hline & & & & & & & & & & & \\
\hline & $\mathbf{N}^{\mathbf{o}}$ & $\%$ & $\mathbf{N}^{\circ}$ & $\%$ & $\mathbf{N}^{\mathbf{0}}$ & $\%$ & $\mathbf{N}^{\circ}$ & $\%$ & $\mathbf{N}^{\mathbf{0}}$ & $\%$ & \\
\hline Escola / Faculdade / Universidade & 2 & $5,9 \%$ & 3 & $8,8 \%$ & 11 & $32,4 \%$ & 12 & $35,3 \%$ & 6 & $17,6 \%$ & 3,50 \\
\hline Prédio ou Condomínio Residencial & 0 & $0,0 \%$ & 1 & $3,2 \%$ & 8 & $25,8 \%$ & 19 & $61,3 \%$ & 3 & $9,7 \%$ & 3,78 \\
\hline Prédio ou Condomínio Comercial & 0 & $0,0 \%$ & 1 & $3,4 \%$ & 8 & $27,6 \%$ & 16 & $55,2 \%$ & 4 & $13,8 \%$ & 3,79 \\
\hline Restaurante & 0 & $0,0 \%$ & 0 & $0,0 \%$ & 9 & $25,0 \%$ & 20 & $55,6 \%$ & 7 & $19,4 \%$ & 3,94 \\
\hline \begin{tabular}{|l|} 
Shopping \\
\end{tabular} & 0 & $0,0 \%$ & 1 & $2,7 \%$ & 1 & $2,7 \%$ & 15 & $40,5 \%$ & 20 & $54,1 \%$ & 4,46 \\
\hline Indústria & 1 & $4,8 \%$ & 3 & $14,3 \%$ & 12 & $57,1 \%$ & 5 & $23,8 \%$ & 0 & $0,0 \%$ & 3,00 \\
\hline Hospital & 0 & $0,0 \%$ & 7 & $28,0 \%$ & 11 & $44,0 \%$ & 5 & $20,0 \%$ & 2 & $8,0 \%$ & 3,08 \\
\hline
\end{tabular}

Figura 5: Resultados das notas atribuídas dos usuários para os as ambientes frequentados

Tendo como base que a satisfação dos usuários pode ser utilizada como um parâmetro de qualidade da manutenção predial, pode-se concluir que a melhor gestão de manutenção é a realizada pelos shoppings e a pior é a realizada pelas indústrias. Esta comparação evidencia o que foi anteriormente explicado sobre a manutenção predial ser um diferencial no produto final da empresa. No caso dos shoppings, o produto final são as vendas das suas lojas, e para isso é preciso atrair os clientes, sendo então a manutenção predial importante, uma vez que 90,3\% dos entrevistados afirmaram importar-se com as condições dos ambientes que frequenta a ponto de querer retornar ou não. Por outro lado, nas indústrias a manutenção predial não agrega valor aos seus produtos, sendo um custo a mais que não tem o seu retorno e por isso a má qualidade na sua gestão, o que poderia ser resolvido com a terceirização ou com o acompanhamento de empresas especializadas.

As duas últimas perguntas do questionário apresentaram para os usuários algumas falhas ou manifestações patológicas e solicitaram que assinalassem conforme dois critérios. Na primeira, deveriam marcar as alternativas com as manifestações mais observadas, e na segunda, as alternativas que mais afetassem a sua sensação de conforto, as respostas estão apresentadas respectivamente nas Tabelas 1 e 2 . As porcentagens indicadas são relativas a cada item, como por exemplo, o item manchas de umidade foi assinalado por 32 dos 38 respondentes destas duas perguntas, o que corresponde a $84,2 \%$. 
Tabela 1 - Manifestações patológicas observadas mais assinaladas

\begin{tabular}{|c|c|c|}
\hline \multirow{2}{*}{$\begin{array}{c}\text { Manifestações } \\
\text { patológicas }\end{array}$} & \multicolumn{2}{|c|}{ Mais observadas } \\
\hline & Quantidade & $\%$ \\
\hline 1. Manchas de umidade & 32 & $84,2 \%$ \\
\hline 2. Falta de limpeza & 31 & $81,6 \%$ \\
\hline $\begin{array}{l}\text { 3. Pintura descascada nas } \\
\text { paredes externas }\end{array}$ & 28 & $73,7 \%$ \\
\hline $\begin{array}{l}\text { 4. Rachaduras nas } \\
\text { paredes }\end{array}$ & 23 & $60,5 \%$ \\
\hline 5. Falta de iluminação & 23 & $60,5 \%$ \\
\hline $\begin{array}{l}\text { 6. Pintura descascada nas } \\
\text { paredes internas }\end{array}$ & 22 & $57,9 \%$ \\
\hline 7. Vazamentos & 16 & $42,1 \%$ \\
\hline $\begin{array}{l}\text { 8. Rachaduras perto de } \\
\text { portas ou janelas }\end{array}$ & 12 & $31,6 \%$ \\
\hline $\begin{array}{l}\text { 9. Descolamento de } \\
\text { azulejos nas paredes } \\
\text { internas }\end{array}$ & 11 & $28,9 \%$ \\
\hline $\begin{array}{l}\text { 10. Descolamento de } \\
\text { azulejos nas paredes } \\
\text { externas }\end{array}$ & 10 & $26,3 \%$ \\
\hline 11. Rachaduras no teto & 9 & $23,7 \%$ \\
\hline 12. Descolamento de piso & 9 & $23,7 \%$ \\
\hline
\end{tabular}

Tabela 2 - Manifestações patológicas relevantes mais assinaladas

\begin{tabular}{|l|c|c|}
\hline \multicolumn{1}{|c|}{$\begin{array}{c}\text { Manifestações } \\
\text { patológicas }\end{array}$} & \multicolumn{2}{c|}{$\begin{array}{c}\text { Mais afetam sensação } \\
\text { de conforto }\end{array}$} \\
\cline { 2 - 3 } Quantidade & \% \\
\hline 1. Falta de limpeza & 31 & $81,6 \%$ \\
\hline 2. Manchas de umidade & 25 & $65,8 \%$ \\
\hline $\begin{array}{l}\text { 3. Rachaduras nas } \\
\text { paredes }\end{array}$ & 20 & $52,6 \%$ \\
\hline $\begin{array}{l}\text { 4. Falta de iluminação } \\
\text { 5. Vazamentos }\end{array}$ & 20 & $52,6 \%$ \\
\hline $\begin{array}{l}\text { 6. Pintura descascada nas } \\
\text { paredes internas }\end{array}$ & 18 & $47,4 \%$ \\
\hline \begin{tabular}{l} 
7. Descolamento de piso \\
\hline 8. Rachaduras no teto
\end{tabular} & 11 & $28,9 \%$ \\
\hline $\begin{array}{l}\text { 9. Pintura descascada nas } \\
\text { paredes externas }\end{array}$ & 10 & $26,3 \%$ \\
\hline $\begin{array}{l}\text { 10. Rachaduras perto de } \\
\text { portas ou janelas }\end{array}$ & 8 & $21,1 \%$ \\
\hline $\begin{array}{l}\text { 11. Descolamento de } \\
\text { azulejos nas paredes } \\
\text { internas }\end{array}$ & 7 & $18,4 \%$ \\
\hline $\begin{array}{l}\text { 12. Descolamento de } \\
\text { azulejos nas paredes } \\
\text { externas }\end{array}$ & 6 & $15,8 \%$ \\
\hline
\end{tabular}

Nota-se que as manchas de umidade e a falta de limpeza são os itens mais observados e também os que mais afetam a sensação de conforto. Descolamentos e rachaduras no teto são em geral pouco observados e pouco influenciam nos usuários. Este tipo de informação é relevante no momento da elaboração dos programas de manutenção, pois um bom programa não é aquele com os melhores resultados, mas sim, o que melhor atenda a satisfação dos usuários.

Comparando o desempenho de cada idem em relação as suas colocações nas duas tabelas, percebe-se que há uma tendência de que quanto mais a manifestação é observada maior é a possibilidade de ela afetar a sensação de conforto. Isto porque as colocações de cada item não sofreram grandes alterações de uma tabela para outra, com exceção de Pintura descascada nas paredes externas (de $3^{\circ}$ na tabela 4 para $9^{\circ}$ na tabela 5 ), rachaduras no teto $\left(11^{\circ}\right.$ para $\left.8^{\circ}\right)$ e descolamento de piso $\left(12^{\circ}\right.$ para $\left.7^{\circ}\right)$, sendo estes dois últimos os menos observados. Estas comparações indicam que ao se programar as atividades de manutenção para satisfazer os usuários, pode-se dar preferência para aquelas que intervenham nas manifestações mais frequentes.

A Figura 5 compara o desempenho de cada item em relação a quantidade de marcações. Apenas três itens (Rachaduras no teto, Vazamentos e Descolamento de piso) foram mais assinalados como relevantes para o conforto do que como observados nas edificações, e somente a falta de limpeza teve o mesmo número de marcações para as duas perguntas. 


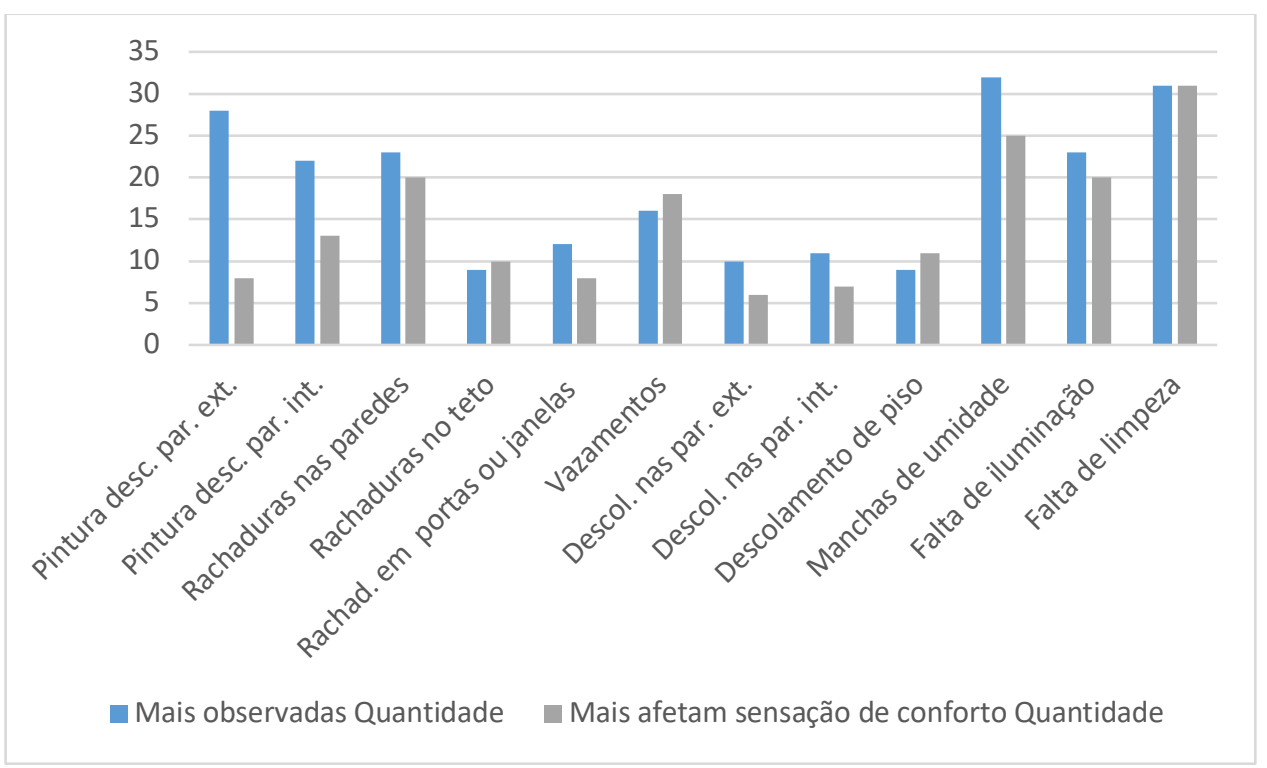

Figura 6: Gráfico das manifestações patológicas

Destaque para o item pintura descascada nas paredes externas que apresentou a maior diferença entre ser observado e influenciar no conforto, cerca de $70 \%$, sendo então ignorado pela maioria das pessoas que veem este tipo de manifestação patológica. Para os demais itens esta porcentagem foi inferior a $50 \%$, ou seja, a maioria das pessoas que os observam sentem-se desconfortáveis. Em relação ao total de marcações das duas perguntas, a que questionava sobre as falhas mais comuns obteve 226 marcações e a que questionava sobre as que influenciavam no conforto obteve 177 marcações, cerca de $22 \%$ a menos.

\section{CONSIDERAÇÕES FINAIS}

Os questionários elaborados e aplicados junto as empresas e aos usuários foram importantes para buscar o objetivo da pesquisa, de identificar a gestão de manutenção predial e qualifica-la. Com os resultados obtidos, pode-se chegar a conclusões que mostram algumas tendências do mercado conforme os interesses de cada empresa e também as opiniões dos usuários em relação ao tema proposto.

Entre as empresas participantes do questionário, 58,3\% delas afirmaram que não possuem programa de manutenção, evidenciando o desconhecimento delas sobre os benefícios de um programa bem executado. Todas as empresas de reforma e manutenção afirmaram que elaboram programas de manutenção, enquanto que as empresas industriais não possuem, mostrando o seu desconhecimento, e enfrentam dificuldades em paralisar as atividades para as intervenções. A maioria das empresas mostrou-se favorável sobre a terceirização da gestão ou execução da manutenção predial como forma de melhorar os serviços e poder concentrar-se nas suas atividades principais, apesar de não ser prática comum.

Em relação aos usuários, 92,5\% disseram que o estado de conservação dos ambientes afeta na sua sensação de bemestar, o que aumenta a importância da manutenção predial como forma de cumprir com o seu papel social. A maioria dos usuários $(70,7 \%)$ também afirmaram que a conservação das edificações é um fator que interfere no momento de escolher ao frequentar um local ou não, e que inclusive pagariam a mais. Quando perguntados se voltariam a um local que se encontrava em más condições na sua primeira visita, 90,3\% mostraram alguma objeção em voltar. Com isso percebe-se que as empresas podem investir em manutenção para atraírem clientes, se este for o seu objetivo.

Os idosos, apesar de estarem em pequeno número na pesquisa, apresentaram uma tendência particular em relação aos jovens e adultos. Mostraram-se favoráveis em pagar a mais para ter melhor bem-estar nas suas moradias, porém não pagariam a mais para os demais ambientes que frequentam.

Comparando as respostas conforme as classes sociais dos participantes do questionário, percebe-se que não houve diferença, ou seja, nas classes sociais mais baixas a porcentagem de pessoas que pagariam a mais por melhores condições dos locais frequentados foi semelhante a registrada nas outras classes, mas é importante salientar que não houve indicação de quanto seriam estes valores adicionais. 
Por último, ficou constatada a importância de colher as opiniões dos usuários como forma de avaliar os serviços de manutenção, conforme as citações do referencial teórico, pois assim pode-se verificar que a melhor gestão de manutenção é a praticada nos shoppings e a pior é a praticada nas indústrias. Isto vai de encontro com o que fora dito anteriormente, que seria indicada a terceirização da manutenção nos ambientes industriais pois não agrega valor ao seu produto final, e poderia ter um serviço de melhor qualidade.

Como trabalhos futuros, indica-se quatro caminhos que poderiam ser seguidos: estudar a gestão de manutenção aplicada especificamente em shoppings para entender os processos que a tornam a de melhor qualidade, comparar os custos em manutenção com e sem programa de manutenção nos ambientes industriais para verificar se estes custos poderiam ser reduzidos, aprofundar a pesquisa dos usuários em relação aos idosos para verificar se há a necessidade de serviços de manutenção específicos para eles e por último realizar uma pesquisa com os usuários para determinar os valores que seriam absorvidos por eles para serviços de melhor qualidade a fim de justificar os investimentos em manutenção.

\section{REFERÊNCIAS}

ANTONIAZZI, M. Manual de operação, uso e manutenção de edificações: elaboração e coleta de dados durante a execução. 2012. 79 f. TCC (Graduação) - Curso de Engenharia Civil, Universidade Federal do Rio Grande do Sul, Porto Alegre, 2012.

ASSOCIAÇÃO BRASILEIRA DE NORMAS TÉCNICAS. NBR 14037: Diretrizes para elaboração de manuais de uso, operação e manutenção das edificações - Requisitos para elaboração e apresentação dos conteúdos. 2 ed. São Paulo: Abnt, 2011. 16 p.

ASSOCIAÇÃO BRASILEIRA DE NORMAS TÉCNICAS. NBR 15575-1: Edificações habitacionais — Desempenho Parte 1: Requisitos gerais. 2 ed. Rio de Janeiro, 2013. 71 p.

ASSOCIAÇÃO BRASILEIRA DE NORMAS TÉCNICAS. NBR 5674: Manutenção de edificações - Requisitos para o sistema de gestão de manutenção. 2 ed. Rio de Janeiro, 2012. 25 p.

BORGES, Carlos Alberto de Moraes. O conceito de desempenho de edificações e a sua importância para o setor da construção civil no Brasil. São Paulo: Epusp, 2008. 19 p.

CAIXETA, D. S. et al. Monitoramento da qualidade do ar interior de uma escola da rede pública localizada no município de Cuiabá-MT. Engineering \& Science, Mato Grosso, v. 1, n. 5, p.20-28, jun. 2016.

CAMPOS, Rodrigo Miguel; VARGAS, Alexandre. Proposta de um plano de manutenção predial preventiva para um edifício residencial. 2014. 19 f. TCC (Graduação) - Curso de Engenharia Civil, Universidade do Extremo Sul Catarinense, Criciúma, 2014.

CASTRO, U. R. Importância da manutenção predial preventiva e as ferramentas para sua execução. $2007.44 \mathrm{f}$. Monografia (Especialização) - Curso de Engenharia Civil, Universidade Federal de Minas Gerais, Belo Horizonte, 2007.

CBIC. Guia nacional para elaboração do manual de uso, operação e manutenção das edificações. Fortaleza: Gadioli Cipolla Branding e Comunicação, 2014. 185 p.

CBIC. Manual de operação, uso e manutenção de edificações: Orientações para Construtoras e Incorporadoras. Brasília: Cbic, 2013.

LACERDA, D. J. de M.; CONCEIÇÃO, G. A.; YONAMINE, M. Manutenção em escolas públicas. 2016.69 f. TCC (Graduação) - Curso de Engenharia Civil, Universidade Santa Cecília, Santos, 2016.

LEMOS, M. A.; ALBERNAZ, C. M. R. M.; CARVAlHO, R. A. Qualidade na manutenção. In: ENCONTRO NACIONAL DE ENGENHARIA DE PRODUÇÃO, 31, 2011, Belo Horizonte. Belo Horizonte: Abepro, 2011. v. 1, p. $1-11$. 
LIMA, Daniel Jádson Noronha. A manutenção na conservação do bom desempenho das edificações ao longo de sua vida útil. 2016. 132 f. TCC (Graduação) - Curso de Engenharia Civil, Departamento de Engenharia Civil, Universidade Federal do Rio Grande do Norte, Natal, 2016.

MAIA, Bárbara Lepca. Análise do fluxo de informações no processo de manutenção predial apoiada em BIM: estudo de caso em coberturas. 2016. 101 f. Dissertação (Mestrado) - Curso de Engenharia de Construção Civil, Setor de Tecnologia, Universidade Federal do Paraná, Curitiba, 2016.

NETO, Jerônimo Cabral Pereira Fagundes. NBR 5674 - Julho 2012 - Requisitos para o sistema de gestão de manutenção - CONSIDERAÇÕES. 2012.

PASCHOAL, Débora Rodrigues de Souza et al. Disponibilidade e confiabilidade: aplicação da gestão da manutenção na busca de maior competitividade. Revista da Engenharia de Instalações no Mar da Fsma, Rio de Janeiro, v. 1, n. 3, jan. 2009. Disponível em: <http://www.fsma.edu.br/EP/Artigos/REV_ENG_3_artigo_3.pdf>. Acesso em: 29 nov. 2016.

SARROUF, Lilian. A importância do manual de uso, operação e manutenção das edificações. In: CONGRESSO BRASILEIRO DE ENGENHARIA DE AVALIAÇÕES E PERÍCIAS, 17., 2013, Florianópolis. Florianópolis: Ibape/sc, 2013.

SCOPEL, Vanessa Guerini. Percepção do ambiente e a influência das decisões arquitetônicas em espaços de trabalho. Revista Eletrônica de Arquitetura e Urbanismo, São Paulo, v. 13, n. 1, p.153-170, jan. 2015.

SILVA, Geraldo Oliveira da. Proposta de Metodologia de Manutenção Predial. 2014. 119 f. TCC (Graduação) Curso de Engenharia Civil, Centro Universitário de Brasília, Brasília, 2014.

SILVA, E. L.; MENEZES, E. M. Metodologia da pesquisa e elaboração de dissertação. $4^{\mathrm{a}}$ ed. Rev. Atual, Florianópolis, Laboratório de Ensino a Distância da UFSC, 2005.

SIQUEIRA, Roger Adriano de. Estudo comparativo entre a manutenção predial preventiva (NBR 5674) e a manutenção real praticada pelos síndicos dos edifícios residenciais em Brasília. 2014. 74 f. TCC (Graduação) Curso de Engenharia Civil, Centro Universitário de Brasília, Brasília, 2014

SURVEYMONKEY. A Escala de Likert explicada. Disponível em: < https://pt.surveymonkey.com/mp/likert-scale/> . Acesso em: 19 dez. 2016.

TRIERVEILER, Tiago da Rocha. O pedágio urbano como forma de desestímulo ao transporte individual motorizado.2015. 122 f. TCC (Graduação) - Curso de Engenharia Civil, Departamento de Engenharia Civil, Universidade Federal do Rio Grande do Sul, Porto Alegre, 2015.

VILlANUEVA, Marina Miranda. A importância da manutenção preventiva para o bom desempenho da edificação. 2015. 144 f. TCC (Graduação) - Curso de Engenharia Civil, Construção Civil, Universidade Federal do Rio de Janeiro, Rio de Janeiro, 2015. 